\title{
Nasal high-flow in acute hypercapnic exacerbation of COPD
}

Jens Bräunlich

Hubert Wirtz

Department of Respiratory Medicine, University of Leipzig, Leipzig,

Germany
Correspondence: Jens Bräunlich

Department of Respiratory Medicine, University of Leipzig, Liebigstrasse 20, Leipzig, 04103, Germany

Fax +49 34I 97। 2450

Email jens.braeunlich@uniklinik-leipzig.de
This article was published in the following Dove Press journal: International Journal of COPD

\section{Introduction}

Since the late 1980s non-invasive ventilatory support (NIV) has become a standard treatment in acute exacerbation of COPD (AECOPD) with hypercapnia. ${ }^{1}$ Although NIV has been shown to be extremely useful in this situation, but up to $30 \%$ of hypercapnic AECOPD patients do not tolerate NIV for several reasons. ${ }^{2}$

Nasal high-flow (NHF) provides a warmed and humidified airflow up to 60 Liter/ min through a specialized nasal cannula. Oxygen admixture is readily available and should be dosed to a desired saturation. ${ }^{3}$ NHF combines a wash-out effect with a decrease in $\mathrm{CO}_{2}$ rebreathing, support of inspiratory flow, a small increase in airway pressure, a lowering of ambient air admixture during inspiration and possibly a beneficial effect of warmed and saturated air in the airways. Together, these effects lead to a stabilization of oxygen delivery at higher respiratory rates, a decrease in the work of breathing noticeable by a lower respiratory rate and reduced hypercapnia. ${ }^{4-6}$

Several studies evaluated the effectiveness of NHF therapy in a variety of clinical situations with effects comparable to NIV., Most of these investigations excluded patients with hypercapnia. It is therefore, impossible to draw meaningful conclusions on the effectiveness of NHF in AECOPD. Several smaller series have observed a significant decrease in partial arterialized carbon dioxide pressure of $\mathrm{CO}_{2}\left(\mathrm{paCO}_{2}\right)$ in chronic hypercapnic COPD patients. ${ }^{4,6}$ There are no data available about other endpoints or in a cohort of solely hypercapnic AECOPD patients.

\section{Methods}

Thirty-eight patients were treated between 2015 and 2017 at the Department of Respiratory Medicine, University hospital Leipzig, Germany. Patients were included if they a) did not tolerate NIV following a regular trial (intolerance of NIV), b) fulfilled AECOPD criteria (Anthonisen), c) had a decrease in $\mathrm{pH}(\mathrm{pH} \leq 7.38)$ and a capillary $\mathrm{paCO}_{2}>45$ mmHg at admission, d) had absence of acute metabolic disorders, and e) did not fulfill criteria for intubation. Initiation of NHF (Softflow 50; TNI medical AG, Würzburg) was titrated to achieve a flow rate with greatest tolerability. Oxygen flow (as part of the total flow) was then adjusted to achieve baseline $\mathrm{SpO}_{2}$ values. Changes in partial pressures of oxygen $\left(\mathrm{paO}_{2}\right)$ and $\mathrm{paCO}_{2}$ as well as $\mathrm{pH}$ in capillary blood gas analysis were monitored closely. NHF was terminated when $\mathrm{pH}$ increased to more than 7.38 or when the patient no longer tolerated the device or had lesser symptoms. Statistical analysis was performed using an ANOVA test (Sigma Plot; Systat Software GmbH, Ekrath, Germany). This study was approved by the University of Leipzig ethics committee (110/18-ek) and registered (NCT03523481). Patients provided written informed 
Table I Parameters during NHF treatment

\begin{tabular}{|c|c|c|c|c|}
\hline \multirow[t]{2}{*}{ Parameters } & \multicolumn{4}{|c|}{ All patients $(\mathrm{pH} \leq 7.38 ; \mathrm{n}=38)$} \\
\hline & Baseline (mean \pm SD) & End (mean \pm SD) & Change (mean \pm SD) & $P$-value \\
\hline $\mathrm{pH}$ & $7.339 \pm 0.041$ & $7.392 \pm 0.048$ & $0.052 \pm 0.048$ & 0.000 \\
\hline $\mathrm{PCO}_{2} \mathrm{mmHg}$ & $67.6 \pm 12.9$ & $58.5 \pm 9.7$ & $-9.1 \pm 8.8$ & 0.001 \\
\hline $\mathrm{pO}_{2} \mathrm{mmHg}$ & $58.3 \pm 15.2$ & $58.3 \pm 17.6$ & - & 0.983 \\
\hline $\mathrm{SO}_{2} \%$ & $85.3 \pm 9.5$ & $86.2 \pm 11.3$ & - & 0.798 \\
\hline $\mathrm{HCO}_{3} \mathrm{mmol} / \mathrm{L}$ & $30.8 \pm 5.1$ & $31.6 \pm 5.3$ & - & 0.636 \\
\hline Base excess $\mathrm{mmol} / \mathrm{L}$ & $6.9 \pm 4.9$ & $7.7 \pm 5.4$ & - & 0.633 \\
\hline NHF flow L/min & - & $25.8 \pm 8.2$ & - & - \\
\hline \multirow[t]{2}{*}{ Treatment time min } & - & $195 \pm 231$ & - & - \\
\hline & \multicolumn{4}{|c|}{ Patients with $\mathrm{pH}<7.35(\mathrm{n}=17)$} \\
\hline $\mathrm{pH}$ & $7.298 \pm 0.046$ & $7.379 \pm 0.051$ & $0.082 \pm 0.060$ & 0.000 \\
\hline $\mathrm{PCO}_{2} \mathrm{mmHg}$ & $73.7 \pm 13.7$ & $59.6 \pm 11.2$ & $-14.2 \pm 10.6$ & 0.002 \\
\hline $\mathrm{pO}_{2} \mathrm{mmHg}$ & $56.9 \pm 14.8$ & $55.6 \pm 20.7$ & - & 0.845 \\
\hline $\mathrm{SO}_{2} \%$ & $84.8 \pm 10.1$ & $84.3 \pm 11.9$ & - & \begin{tabular}{|l|}
0.904 \\
\end{tabular} \\
\hline $\mathrm{HCO}_{3} \mathrm{mmol} / \mathrm{L}$ & $31.6 \pm 5.5$ & $32.5 \pm 5.6$ & - & 0.661 \\
\hline Base excess $\mathrm{mmol} / \mathrm{L}$ & $7.4 \pm 5.3$ & $8.5 \pm 5.7$ & - & 0.591 \\
\hline NHF flow L/min & - & $26.3 \pm 7.9$ & - & - \\
\hline Treatment time min & - & $252 \pm 25 I$ & - & - \\
\hline
\end{tabular}

Notes: Changes in blood gas analyses data, usage time and flow rates during NHF therapy in all patients and in the subgroup with $\mathrm{pH}<7.35$. All data are organized as mean \pm SD. “-” indicates no significant differences to report.

Abbreviation: NHF, nasal high-flow.

consent. The study was carried out in accordance with the principles of the Declaration of Helsinki.

\section{Results}

A significant treatment effect was seen in mean capillary blood $\mathrm{pH}$ and in mean $\mathrm{paCO}_{2}$ (Table 1, Figure 1). Greatest improvements in $\mathrm{pH}$ and $\mathrm{paCO}_{2}$ were found in 17 patients with baseline $\mathrm{pH}<7.35$ (Table 1).

\section{Conclusion and limitation}

To our knowledge, this is the first observation evaluating NHF in a cohort with solely hypercapnic (partly acidotic)
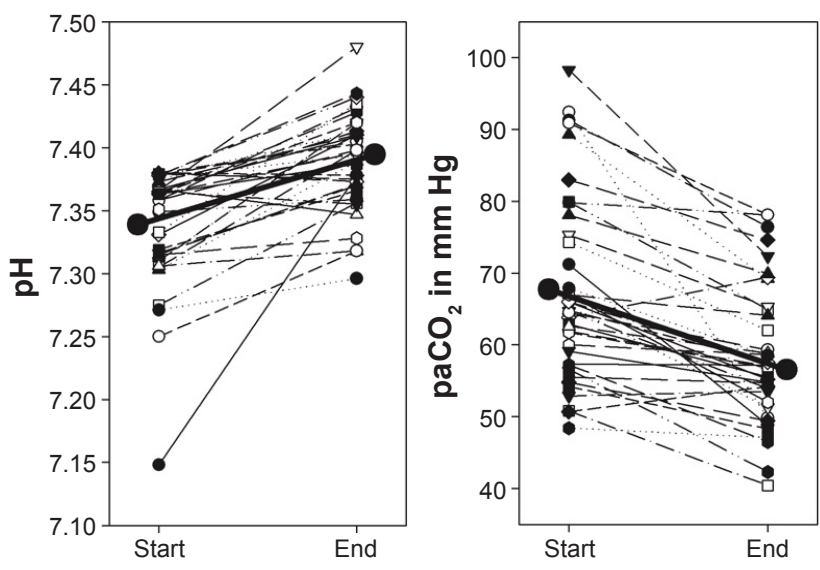

Figure I Changes in $\mathrm{pH}$ and $\mathrm{paCO}_{2}$ in all patients; the bold line marks mean values; $P<0.05$.
AECOPD patients. We found significant improvements of $\mathrm{pH}$ and $\mathrm{paCO}_{2}$. Our study demonstrates that using NHF in severe-to-moderate acidotic and non-acidotic hypercapnic AECOPD patients who did not tolerate NIV is useful.

The limitation of this investigation is best described by its retrospective nature with the lack of a control group. The number of patients was low but appears to be sufficient for a first answer as to whether NHF may be useful in hypercapnic AECOPD patients.

\section{Disclosure}

The authors report travel grants, non-financial support (equipment), and lecture fees from TNI medical AG and report no other conflicts of interest in this work.

\section{References}

1. Rochwerg B, Brochard L, Elliott MW, et al. Official ERS/ATS clinical practice guidelines: noninvasive ventilation for acute respiratory failure. Eur Respir J. 2017;50(2):1602426.

2. Confalonieri M, Garuti G, Cattaruzza MS, et al. A chart of failure risk for noninvasive ventilation in patients with COPD exacerbation. Eur Respir J. 2005;25(2):348-355.

3. Frat JP, Thille AW, Mercat A, et al. High-flow oxygen through nasal cannula in acute hypoxemic respiratory failure. $N$ Engl J Med. 2015; 372(23):2185-2196.

4. Bräunlich J, Köhler M, Wirtz H. Nasal highflow improves ventilation in patients with COPD. Int J Chron Obstruct Pulmon Dis. 2016;11: $1077-1085$. 
5. Bräunlich J, Mauersberger F, Wirtz H. Effectiveness of nasal highflow in hypercapnic COPD patients is flow and leakage dependent. BMC Pulm Med. 2018;18(1):14.

6. Bräunlich J, Seyfarth HJ, Wirtz H. Nasal High-flow versus non-invasive ventilation in stable hypercapnic COPD: a preliminary report. Multidiscip Respir Med. 2015;10(1):27.
7. Hernández G, Vaquero C, Colinas L, et al. Effect of postextubation high-flow nasal cannula vs noninvasive ventilation on reintubation and postextubation respiratory failure in high-risk patients: a randomized clinical trial. JAMA. 2016;316(15):1565-1574.

International Journal of COPD

\section{Publish your work in this journal}

The International Journal of COPD is an international, peer-reviewed journal of therapeutics and pharmacology focusing on concise rapid reporting of clinical studies and reviews in COPD. Special focus is given to the pathophysiological processes underlying the disease, intervention programs, patient focused education, and self management protocols.
Dovepress

This journal is indexed on PubMed Central, MedLine and CAS. The manuscript management system is completely online and includes a very quick and fair peer-review system, which is all easy to use. Visit $\mathrm{http}: / / \mathrm{www}$.dovepress.com/testimonials.php to read real quotes from published authors.

Submit your manuscript here: http://www.dovepress.com/international-journal-of-chronic-obstructive-pulmonary-disease-journal 